\title{
PENINGKATAN KUALITAS LAYANAN KONSUMEN PADA RADIO RADIO DAKWAH ISLAMIAH 100,5 Fm
}

\author{
Arif Agung Setiawan \\ Department of Management FEB UMM \\ E-mail: aree.soul@yahoo.com
}

\begin{abstract}
The purpose of this study was to determine the quality of service on 100.5 FM Radio Dakwah Islamiah, to know what service attributes less value performance and find out what attributes can be developed as a new added value, and to identify targets and priority repairs to be carried out by RDI 100.5 FM. The analysis tool used is Quality Function Deployment (QFD) by means House of Quality (HOQ) to convert the customer's voice directly to the technical requirements of the services produced. This study uses six operational variables, namely quality management, design of products and services, layout, location, process design and capacity, human resources in the job design attributes translate what the customer needs. The results of analysis shown that the quality of existing services in RDI 100.5 FM that is pretty good, but need repair and upgrading to meet the expectations of listeners is on the attributes of the hospitality crew, modulation radio announcer voice clarity. It is also shown to attribute that has a value that is less performance such as signal coverage, the number of pauses, specialization of employees, and knowable steps can companies do to improve the quality of service that has been sorted based on targets and priorities.
\end{abstract}

Keywords: Quality Function Deployment (QFD), House of Quality (HOQ), Quality

\section{PENDAHULUAN}

Industri jasa saat ini berkembang pesat seiring dengan era globalisasi, berkembang pesatnya industri baik manufaktur atau jasa menimbulkan banyak persaingan dan menuntut perusahaan untuk semakin meningkatkan kegiatan operasional guna meningkatan kualitas.

Adanya persaingan yang ketat inilah perusahaan harus selalu meningkatkan tata kelola dan meningkatkan kualitas produk, guna mendapatkan kepuasan dan loyalitas dari konsumen. Untuk mendapatkan kepuasan pelanggan maka diperlukan tata kelola operasional yang baik dalam perusahaan. Tata letak ini menjadi titik penting dalam perkembangan perusahaan itu sendiri.

Penilaian konsumen akan kualitas bersifat subyektif. Kualitas penting bagi perusahaan karena kualitas produk sangat memberikan konstribusi yang besar terhadap kepuasan pelanggan. Akan tetapi konsep kualitas sering dianggap sebagi tolak ukur kebaikan atau kehandalan dari suatu produk ataupun jasa yang terdiri atas kualitas desain dan kualitas kesesuaian. 
Kualitas pelayanan baik industri manufaktur ataupun jasa merupakan manivestasi dari kualitas indutri itu tersebut. Daya saing sebuah produk akan sangat ditentukan oleh pengelolaan sumber daya perusahaan atau industri hingga mampu memenuhi standar-standar kualitas. Untuk mencapai standar kualitas dibutuhkan pengendalian kualitas dari proses input, produksi hingga output serta pemberian jaminan kualitas.

Masalah-masalah tentang manajemen jasa semakin menarik. Konsep tentang produktivitas dalam bisnis jasapun disoroti, mengingat jasa berbeda dengan manufaktur. Mengukur produktivitas jasa sangat tergantung pada penilaian kuantitas dan kualitas input dan output dari jasa tersebut. Perusahaan membutuhkan strategi untuk meningkatkan kepuasan konsumen dan diikuti oleh usaha untuk menurunkan biaya pada aktivitas yang terkait. Dengan meningkatkan produktivitas dan kualitas jasa diharapkan meningkatkan nilai perusahaan.

Pada perusahaan penyediaan jasa, bahan baku adalah keterampilan tenaga kerja,. produktivitas penting bagi perusahaan jasa, dimana yang dipasarkan itu adalah keterampilan atau asuransi dan membutuhkan kecakapan setiap orang dalam perusahaan tersebut.

Pengukuran

kepuasan pelanggan merupakan elemen penting dalam menyediakan pelayanan yang lebih baik, lebih efesien dan lebih efektif. Apabila pelanggan merasa tidak puas terhadap suatu pelayanan yang disediakan, maka pelayanan tersebut dapat dipastikan tidak efektif dan tidak efesien.
Untuk menyediakan pelayanan yang baik maka diperlukan pengendalian kualitas. Pengendalian kualitas adalah aktivitas untuk menjaga, mengarahkan, mempertahankan dan memuaskan tuntutan konsumen secara maksimal. Tujuan pengendalian kualitas adalah untuk mengawasi tingkat produksi melalui banyak tahapan produksi atau mengetahui sejauh mana proses dan hasil produk (jasa) yang dibuat sesuai dengan standar yang ditetapkan perusahaan (Prawiroentono, 2002; 75)

Menurut Cohen (1995), QFD adalah metodologi terstruktur yang digunakan dalam proses perancangan dan pengembangan produk untuk menetapkan spesifikasi kebutuhan dan keinginan konsumen, serta mengevaluasi secara sistematis kapabilitas produk atau jasa dalam memenuhi kebutuhan dan keinginan konsumen. dimana pengembangan produk berdasarkan keinginan konsumen dengan menggunakan 6 variabel yaitu manajemen mutu, desain produk dan jasa, tata letak, lokasi, desain proses dan kapasitas, SDM dan rancangan kerja.

Pada perkembangannya radio adalah media komunikasi yang bertahan dari masa kemasa, media ini memiliki kecepatan dan mobilitas yang tinggi dan memiliki kedekatan langsung terhadap pendengar tidak hanya sebagai media hiburan, radio juga berfungsi ganda yaitu sebagai media komunikasi dan tak jarang sebagai pusat informasi bagi masyarakat. Radio dakwah islamiah didirikan pada tahun 2006, terletak dikota Malang tepatnya di jalan Kapten Piere Tendean 1c/7c Jagalan, 
Malang. Radio ini didirikan oleh yayasan masjid An-nur Jagalan saleyer dengan membentuk atau mendirikan Perkumpulan Komunitas Radio Suara Hati muslim dengan sebutan udaranya adalah Radio Dakwah Islamiah (RDI) An-nur.

Tujuan didirikan RDI An-nur

Fm adalah untuk menghalau pengaruh- pengaruh yang berdampak negatif sekaligus untuk memberikan wawasan bernilai keagamaan kepada masyarakat kota malang dan menciptakan masyarakat yang berilmu agama, yang bisa mengamalkan ilmu tersebut dalam kehidupan sehari hari sehinga tercipta masyarakat yang tenang, tentram dan sakinah dalam rumah tangga mereka.

Dalam menjalankan fungsi informasionalnya, Radio Dakwah Islamiah $100.5 \mathrm{Fm}$ membuat khalayak lebih terlibat dalam masalah aktual dan dekat pada lingkungan religius dan memberikan pencerahan pada umat tentang syariat Islam yang benar dengan adanya sajian-sajian pengajian yang disiarkan setiap harinya. Meskipun struktur sentralistis dapat mensuplai informasi yang bersifat nasional dan internasional di dunia islam, namun informasi yang memenuhi nilai proximity tetap sebagai prioritas bagi radio ini.

Dari sajian-sajian inilah radio ini mempunyai segmentasi pendengar yang berbeda dari radio-radio umum. Radio Dakwah Islamiah 100.5 Fm mempunyai pendengar yang majemuk dari berbagai kalangan, mulai kalangan atas ataupun bawah bisa disatukan dengan lingkup siaran berbasis religi ini. Dari sinilah kekuatan radio yang berbasis religi ini mempunyai kepuasan batin dan keloyalan dari pendengarnya untuk tetap bisa eksis di udara.

Dalam hal ini faktor kepuasan pelanggan menjadi topik utama yang menjadi topik kajian mendalam, sehingga bisa kita ketahui bahwasanya sejauh mana pendengar Radio Dakwah Islamiah mendapatkan rasa kepuasan dari sajian sajian acara yang ada dan faktor-faktor apa saja yang menjadi atribut dalam pencapaian kepuasan pelanggan dan apa yang harus diperbaiki dalam program acara yang ada untuk meningkatkan kepuasan dan loyalitas pendengar

Akan tetapi sering terjadi keluhan atau complain yang sering masuk di RDI 100.5 Fm hal seperti dilampiran 14. Hal ini dimungkinkan akan mengurangi kepuasan pelanggan yaitu seperti ditampilkan pada tabel 1 .

Metode penelitian pada Radio Dakwah Islamiah ini akan banyak membantu dalam melihat sejauh mana performance radio dalam layanan terhadap pendengar dan akan banyak membantu peningkatan kualitas dan mengetahui pelayanan apa saja yang dinilai kurang oleh para pendengar, selanjutnya Radio Dakwah Islamiah dalam hal ini akan akan menerjemahkan kedalam kebutuhan teknis yang relevan untuk memenuhi kebutuhan pendengar dan pada bidang operasional mengetahui mana yang diprioritaskan untuk perbaikan dan menciptakan sesuatu yang baru sesuaiharapan pendengar. 
Tabel 1. Daftar Keluhan Pendengar

\begin{tabular}{|c|c|}
\hline Item & Keluhan \\
\hline Sinyal radio & $\begin{array}{l}\text { Kejelasan sinyal radio yang kadang tidak jelas, selain itu } \\
\text { didaerah tertentu terkadang sinyal RDI } 100.5 \text { Fm sering } \\
\text { muncul tenggelam }\end{array}$ \\
\hline $\begin{array}{l}\text { Pembahasan } \\
\text { pemateri }\end{array}$ & $\begin{array}{l}\text { Topik yang dibahas saat siaran dan hal hal yang berkaitan } \\
\text { dengan proses siaran. }\end{array}$ \\
\hline $\begin{array}{l}\text { Informasi } \\
\text { program }\end{array}$ & $\begin{array}{l}\text { Acara ini seperti pukul penayangan, jadwal siaran ulang yang } \\
\text { terkadang tidak disiarkan terlebih dahulu oleh crew }\end{array}$ \\
\hline Modulasi & $\begin{array}{l}\text { Modulasi radio dari RDI } 100.5 \mathrm{Fm} \text { terkadang naik turun dan } \\
\text { tidak stabil }\end{array}$ \\
\hline Refrensi & Sumber refrensi atau buku yang digunakan pemateri \\
\hline $\begin{array}{l}\text { Ruang tamu } \\
\text { atau } \\
\text { pelayanan }\end{array}$ & $\begin{array}{l}\text { Kenyamanan ruang pelayanan yang ada diradio yang kadang } \\
\text { pendengar selalu berjubel dan antri lama saat berkunjung } \\
\text { keradio }\end{array}$ \\
\hline $\begin{array}{l}\text { Produktivita } \\
\text { S }\end{array}$ & Produktivitas RDI $100.5 \mathrm{Fm}$ dalam membuat jeda yang kurang \\
\hline
\end{tabular}

Berdasarkan uraian dan latar belakang yang dituliskan maka penelitian diatas maka judul yang diambil adalah "Peningkatan Kualitas Layanan Konsumen Pada Radio Dakwah Islamiah 100.5 Fm"

Agar penelitian yang dilakukan tetap relevan dengan tujuan penelitian, sehingga tujuan penelitian dapat dicapai dengan baik maka penelitian ini hanya meneliti proses pelayanan kepada pendengar yang ada pada Radio Dakwah Islamiah 100.5 FM.

Adapun tujuan penelitian yang ingin dicapai dalam penelitian ini adalah untuk mengetahui kualitas pelayanan pada Radio Dakwah Islamiah $100.5 \mathrm{Fm}$, atribut pelayanan apa saja yang kurang nilai performanya dan tentang atribut apa saja yang dapat dikembangkan sebagai nilai tambah baru serta mengetahui target dan prioritas perbaikan yang akan dilakukan oleh RDI 100.5 Fm.

\section{TINJAUAN PUSTAKA}

Untuk dapat mengelola
ataupun mengatur operasional perusahaan, maka diperlukan keputusan-keputusan yang harus diambil. Salah cara yang dapat dilakukan adalah dengan 10 keputusan manajemen operasional yang dinyatakan oleh Hazer dan Render (2009:4) yaitu: kualitas, perancangan barang dan jasa, perancangan proses dan kapasitas, pemilihan lokasi, perancangan tata letak, sumber daya manusia dan perancangan pekerjaan, manajemen rantai pasok, persedian, penjadwalan dan pemeliharaan.

Implementasi QFD secara garis besar menurut Nasution (2005) dibagi dalam tiga tahap yaitu tahap pengumpulan Voice of Customer, tahap penyusunan House of Quality dan tahap analisa dan interpretasi

Langkah-langkah untuk menyusun House of quality (HOQ) menurut Nasution (2001) yaitu 
customer need, planning matrix, technical response, relationship matrix, technical correlation, technical response priorities, competitive technical benchmarks dan target.

\section{METODE PENELITIAN}

Jenis penelitian yang digunakan dalam penelitian ini adalah menggunakan aplikasi model (Applied research), yaitu penelitian yang menekankan pada pemecahan masalah masalah praktis yang diarahkan untuk menjawab pertanyaan spesifik dalam rangka penentuan kebijakan, tindakan atau kinerja tertentu (Indrianto dan Supomo,2002).

Variabel dan definisi operasional variabel yang digunakan dalam penelitian ini adalah yang pertama kualitas, indikator yang digunakan didasarkan pada beberapa unsur teori Six Sigma yaitu inputs, processes dan output, yang kedua adalah desain produk dan jasa, indikator terdiri dari beberapa 4 unsur tingkatan produk jasa, yaitu produk inti/generik, terdiri atas jasa dasar, produk yang diharapkan, produk tambahan dan produk potensial, yang ketiga adalah tata letak, indikator yang digunakan didasarkan pada strategi tata letak dengan berfokus pada lingkungan hidup dan estetika, yang keempat adalah lokasi, indikator yang digunakan didasarkan pada beberapa aspek, selanjutnya yang kelima yaitu desain proses dan kapasitas, indikator yang digunakan didasarkan pada strategi proses dan kapasitas dan yang terakhir yaitu sumber daya manusia dan rancangan pekerjaan, indikator didasarkan pada kemampuan mental, fisik, pengetahuan dan keahlian

Populasi yang dimaksud dalam penelitian ini adalah seluruh pendengar Radio Dakwah Islamiah 100.5 Fm yang ada di kota Malang. Penelitian ini menggunakan tehnik metode Snowball Sampling. Responden Pendengar yang digunakan sebanyak 37 responden dengan pembagian 30 responden dari pendengar RDI 100.5 Fm dan 7 responden dari karyawan RDI 100.5 Fm

Ada dua jenis data yang digunakan dalam penelitian ini, yaitu data primer adalah data yang secara khusus dikumpulkan untuk kebutuhan riset yang sedang berjalan (Arikunto, 2010).

Data yang diperoleh dari pengamatan peneliti yaitu merupakan variabel-variabel dalam penelitian yang meliputi variable yang akan digunakan yaitu manajemen mutu, desain jasa, tata letak, lokasi , desain proses dan kapasitas, serta SDM dan rancangan kerja yang ada di RDI 100.5 Fm

Data sekunder adalah data yang dikumpulkan tidak hanya untuk keperluan riset saja (Arikunto, 2010),didapat dari studi literatur yang berhubungan dengan masalahmasalah data tersebut yaitu tentang dokumentasi perusahaan, dan seluruh kegiatan operasional Radio Dakwah Islamiah $100.5 \mathrm{Fm}$, jurnal-jurnal dan buku yang membahas tentang QFD.

Teknik pengumpulan data pada penelitian ini yaitu wawancara, data-data yang diperoleh dari teknik wawancara ini adalah tentang seputar manajemen operasional yang digunakan, dan mengenai variabel- 
variabel yang berhubungan dengan persoalan apa saja mengenai permasalahan yang ada di Radio Dakwah Islamiah 100.5 FM, selanjutnya dengan kuesioner. Dalam hal ini pernyataan atau pertanyaan yang diperoleh yaitu mengenai atribut pelayanan meliputi pelayanan atau variabel yang diinginkan pendengar dalam peningkatan kualitas layanan Radio Dakwah Islamiah 100.5 fm, lalu dokumentasi yang berkaitan dengan dokumen internal yang berisi aturan-aturan atau instrumen dalam menjalankan kegiatan operasional di radio dan dokumen eksternal yang berisi bahan bahan seperti jurnal.

Pengukuran validitas pada penelitian ini menggunakan persamaan (Sugiono, 1999) sebagai berikut:

$r_{x y}$
$\sqrt{\left\{\left(n \sum X\right)^{2}-\left(\sum X\right)^{2}\right\}\left\{\left(n \sum Y\right)^{2}-\left(\sum Y\right)^{2}\right.}$

Keterangan:

$\mathrm{r}=$ Korelasi produk moment

$\mathrm{XY}=$ Jumlah perkalian skor item

dengan skor total

$\mathrm{X}^{2} \quad=$ Jumlah skor kuadrat item

$\mathrm{Y}^{2} \quad=$ Jumlah skor kuadrat item

$\mathrm{N}=$ Jumlah sampel

Tolak ukur yang digunakan apabila angka korelasi (r) hitung > dari $r$ table pada taraf signifikan 5\% maka pernyataan tersebut dinyatakan valid.

Dalam pengujian ini menggunkakan rumus reliability analysis Alpha Cronbach. Rumus tersebut menurut (Sugiyono, 1991) ditulis sebagai berikut:

$$
\begin{array}{ll}
\mathrm{r} & =\left(\frac{K}{K-1}\right)\left(1-\frac{\sum \sigma_{b}^{2}}{\sigma_{t}^{2}}\right) \\
\mathrm{r} & =\text { Reliabilitas keseluruhan } \\
\text { item } &
\end{array}
$$

$\mathrm{K}=$ Banyak butiran pertanyaan

$\sum \sigma_{\mathrm{b}}^{2}=$ Jumlah varians item

$\sigma_{\mathrm{t}}^{2} \quad=$ Varians total

Kriteria pengujiannya adalah apabila nilai $r$ hitung $>r$ tabel, maka pernyataan dinyatakan reliabel, dan sebaliknya apabila nilai $r$ hitung $<r$ tabel, maka pernyataan dinyatakan tidak reliabel.

Analisis data melalui tahaptahap QFD antara lain, Dudung(2012) yaitu tahap pengumpulan suara (voice of customer) dan matriks perencanaan ( planning matrix) terdiri dari performasi kepuasan customer untuk produk yang ada pada saat ini (customer satisfaction performance), performasi kepuasan pesaing (competitive satisfaction performance), sasaran (goal), improvement ratio, titik penjualan (sales point), pembobotan (raw weight), normalisasi pemboboton (normalized raw weight), respon teknis (technical response), relationship matrix, technical correlation, prioritas (technical respons priority), benchmarking, sasaran (target).

Penelitian ini menggunakan skala semantic differensial. Dengan menggunakan semantic differensial nilai semantic setiap kosa kata emosi dapat dipahami secara sistematis.

\section{HASIL PENELITIAN DAN PEMBAHASAN}

Berikut sesuai dengan perumusan masalah dan hasil olah data dari penelitian yang dilakukan,Penelitian bertujuan untuk mengetahui indikator kualitas jasa yang seharusnya dapat ditingkatkan oleh RDI 100.5 Fm dengan menggunakan metode penelitian QFD (Quality Function Deployment), 
Untuk mengetahui indikator apa saja yang dapat meningkatkan kualitas layanan pada RDI 100.5 Fm berikut langkah langkahnya menggunakan metode QFD (Quality Function Deployment), yang pertama matriks kebutuhan pendengar RDI 100.5 Fm. Pada tahap ini mengumpulkan suara konsumen dengan interview dan observasi dokumentasi, tentang daftar keluhan, keinginan atau complain dari pendengar yang di sampaikan ke call center radio. Yang kedua, matriks perencanaan (planning matriks), matriks perencanaan terdiri dari 7 yang berbeda yaitu Importance to customer (ITC).

Pada penilaian tertingi di tahap Ict ini mengartikan bahwa pendengar sangat menginginkan adanya keramahan dari crew radio saat melayani pendengar, radio mampu memberikan topik bahasan yang jelas bermutu dan mudah untuk dipahami oleh pendengar, selain itu dengan responden memberikan nilai 4.7 pada atribut refrensi yang digunakan pendengar mengharapkan bahwa refrensi yang digunakan aman dan terpercaya sesuai tuntunan Rosulluloh SAW, dan juga akses dari pendengar untuk mendengarkan siaran radio ini bisa dimudahkan dengan kecanggihan tehnologi lewat media sosial. Yang kedua, customer satisfaction performance (CuSP).

Nilai Customer Satisfaction performance mempunyai nilai rata rata 3,9 nilai ini mempunyai makna bahwa tingkat kepuasaan pelanggan terhadap pelayanan RDI 100.5 Fm yaitu baik akan tetapi perlu adanya peningkatan pelayanan untuk memaksimalkan kualitas layanan sehingga dapat loyalitas dari pendengar. Yang ketiga, competitive satisfaction performance (CoSP). Pada tahap ini penilaian pendengar berdasarkan perbadingan pelayanan yang diterima dari radio $\mathrm{Al} \mathrm{umm} \mathrm{rata}$ rata nilai kepuasan pelanggan terdapat pada nilai 4,0 yang artinya kepuasan pendengar terhadap pelayanan radio pesaing yaitu baik. Yang keempat, goal. Pada penentuan nilai goal didapat dengan wawancara dengan pihak RDI 100.5 Fm dan diskusi dengan peneliti, nilai goalnya yaitu 4 dan 5 karena pihak management mengananggap penilaian ini merupakan target kepuasan pendengar yang ingin dicapai oleh perusahaan berdasarkan tingkat kepuasan yang sebenarnya. Kelima, improvement ratio. Rasio pengembangan diperoleh dengan caranilai Goal dibagi Customer Satisfaction Performance.

Hasil perhitungan penilaian dibagi menjadi 3 kriteria yaitu, untuk nilai kesulitan tertinggi diatas nilai 1.5, untuk kesulitan sedang antara 1,2 - 1,4 ,sedangkan untuk tingkat kesulitan rendah yaitu antara nilai 1.0 - 1.9. Keenam, Sales Point. Nilai Sales point ditentukan oleh pihak RDI 100.5 Fm, dan digunakan untuk mengetahui seberapa kuat penjualan terhadap atribut atribut apabila atribut atribut tersebut terpenuhi, berdasarkan rata rata nilai sales point pada tabel diatas maka memiliki nilai 1,2 dan 1,5. pihak radio memberikan 6 skor dengan nilai 1,2 dan sisanya 26 indikator dengan nilai 1,5. Ketujuh, Raw Weight dan Normalized Raw Weight dari pengolahan data keduanya didapatkan identifikasi bahwa langkah awal perencanaan perbaikan kualitas jasa dititikkan pada hal yang mendasar sebagai langkah awal perencanaan atau 
perbaikan kualitas dan sistem pelayanan pada pendengar dititik beratkan pada atribut dengan nilai tertinggi yaitu jangkauan sinyal dan kekuatan siaran di RDI 100,5 Fm. Matriks Karakteristik Teknis (Substitute Quality Characteristics) atau Respon Teknis RDI 100.5 Fm.

Respon teknis ini diperoleh dari wawancara dengan pihak management RDI 100.5 Fm dengan membawa data penyebaran kuesioner kepuasan pelanggan, didapatkan data bahwa ada 18 indikator terdapat nilai kepuasan pelanggan berada diangka 3. Berikutnya, yang ketiga, matriks hubungan (relationship matrix). Pada fase ini nilai 9 pada indikator yang berarti sangat kuat hubungannya bila diadakan perbaikan sesuai dengan respon teknis dan nilai 3 yang berarti jika dilakukan perbaikan pada respon teknis maka hubungan pengaruh sedikit hubungannya. Keempat, matriks teknis (relationship matrix). Matriks ini meliputi Priorities technical response, benchmarking dan target.

\section{SIMPULAN}

Berdasarkan atas hasil penelitian dan pembahasan, maka dapat ditarik kesimpulan antara lain bahwa kualitas pelayanan yang dilakukan oleh Radio Dakwah Islamiah 100.5 Fm ini adalah cukup baik, tetapi perlu perbaikan dan peningkatan untuk memenuhi harapan pendengar, berikutnya atribut atribut yang mempunyai nilai kualitas pelayanan yang rendah dan memerlukan perbaikan serta peningkatan kualitas pelayanan antara lain terdapat 20 indikator yaitu meliputi : Lokasi radio dengan citra demografi wilayah yang islami, sajian program untuk semua kalangan dan umur yang, Jumlah penyiar dan karyawan lainnya di radio, Kemampuan karyawan Radio dalam melayani pertanyaan dan keluhan pendengar, Kajian Radio atau program acara, Akses radio, Jumlah Program acara baru Radio, Topik pembahasan yang disiarkan Radio, Atsmotsfer kerja di radio, Program acara di Radio, Kemampuan radio menerjemahkan keinginan pelanggan, Jumlah studio untuk memenuhi siaran di radio, Produktifitas kerja di Radio, Suara penyiar dan pengisi acara Radio dalam membawakan acara, Radio mampu memberikan sarana hiburan dan informasi, Jumlah jeda baru di Radio, Jangkauan sinyal atau kekuatan siaran, Kemampuan karyawan Radio dengan spesialisasi kerja, Perangkat tehnologi yang ada di radio (peralatan siaran, internet.

Setelah mengetahui kelemahan dari atribut kualitas pelayanan yang dimiliki, maka dengan tahap tahap QFD (Quality Function Deployment) peningkatan kualitas layanan yang dapat menjadi target dan prioritas untuk segera atau perlu dilakukan adalah penambahan tenaga kerja (Crew, penyiar dan pemateri radio), melakukan penataan, pengawasan dan penjelesan secara khusus terhadap job desk, peningkatan tehnologi dengan update tehnologi dan penerapan terbaru, melakukan respon yang ramah cepat dan tepat dalam melayani pendengar, memperkuat kanal RDI 100.5 Fm dengan melaporkan ke KPID atau BalMon, melakukan workshop dan pelatihan bagi penyiar RDI 100.5 Fm, meningkatan kinerja crew, memperbaiki dan menambah daya 
pemancar siaran, melakukan umpan balik kepada pendengar dengan kritik atau saran, menampung keinginan pendengar dan manuangkan didalam program acara dengan koridor syar'i, menambah atau membuat program acara dan jeda baru yang lebih informatif dan variatif

Hasil dari penelitian ini bisa digunakan sebagai cara untuk meningkatkan kualitas pelayanan perusahaan karena dengan menerapkan metode QFD perusahaan akan mengetahui letak kekurangan perusahaan serta mengetahui hal-hal yang menjadi keinginan konsumen dalam pelayanan yang dilakukan oleh perusahaan. Demikian yang bisa dilakukan oleh perusahaan dengan melihat respon teknis dari tahap QFD yang sudah dilakukan.

RDI 100.5 Fm harus lebih memfokuskan dan mencoba memperbaiki terhadap prioritas persyaratatan pendengar, yaitu berkaitan dengan pelayanan siaran, program acara, dan pelayanan lainnya yang dinilai kurang nilai performasinya, untuk menilai respon akan kinerja RDI 100.5 Fmperlu melakukan umpan balikkepada pendengar setiap bulannya, agar dapat meningkatkan kualitas produk dan pelayanan. Karena lingkungan usaha yang selalu dinamis membutuhkan perbaikan yang terus menerus sesuai dengan prinsip peningkatan mutu.

\section{DAFTAR PUSTAKA}

Heizer, Jay dan Rander, Barry.2012.Manajemen Operasi; Edisi Ketujuh, Buku satu, Salemba Empat, Jakarta.

Nasution, M. N.2005.Manajemen Mutu Terpadu (Total Quality Management)
Edisikedua.Jakarta : Ghalia Indonesia.

Agus Dudung, M.pd. 2012 Merancang Produk. Bandung: PT Remaja Rosdakarya

Sumarwan, U. 2004. Perilaku Konsumen Teori dan Penerapannya dalamPemasaran. CiawiBogor: Ghalia Indonesia.

Simamora. 2002. Panduan Riset Perilaku Konsumen. Jakarta: PT Gramedia PustakaUtama.

Gazpers, V. 1998.Manajement Produksi Total Strategi Peningkatan Produktivitas Peningkatan Bisnis Global. Jakarta : PT. Gramedia Pustaka Utama.

Hepi Risenasari. 2009. Penerapan Metode Quality Function Deployment (QFD) Dalam Upaya Peningkatan Kualitas Pelayanan Restoran Pringjajar Kabupaten Pemalang Jawa Tengah.[Skripsi] Departemen agribisnisFakultas ekonomi dan manajemenInstitut pertanian bogor.

Henson, Helo. 2007. Membangun kepuasan pelanggan melalui penggunaan qualityfunction deployment (qfd) pada café seberang cabang bogor. [Skripsi].Bogor :Jurusan Ilmu-ilmu Sosial Ekonomi Pertanian. Institut Pertanian Bogor.

Perwira, Muhammad Adhi. 2007. Penerapan metode quality function deploymentdalam penentuan prioritas bagi peningkatan kualitas pelayanan taman wisata 
mekarsari [Skripsi]. Bogor : Program Studi Manajemen Agribisnis FakultasPertanian, Institut Pertanian Bogor

Umar, Husein. 2005. Riset Pemasaran dan Perilaku Konsumen. Jakarta: PT. Gramedia Pustaka Utama.

Kotler, P.1997. Manajemen Pemasaran : Analisis, Perencanaan. Implementasi, dan

Pengendalian. Jilid I. Jakarta : PT. Prenhalindo.
Gazpers, V. 1998.Manajement Produksi Total Strategi Peningkatan Produktivitas

Peningkatan Bisnis Global.Jakarta :PT. Gramedia Pustaka Utama.

Hakim nasution, Arman, 2008.Manajemen Industri, Jogjakarta: andi offset

Kotler, Philip, 1997, Marketing Management : Analysis, Plannin, implementation, and Control, Ninth Edition, PrenticeHall International, Inc. New Jersey. 